\title{
SISTEM PEREKOMENDASI DENGAN SINGULAR VALUE DECOMPOSITION DAN TEKNIK SIMILARITAS PEARSON CORRELATION
}

\author{
Rimbun Siringoringo ${ }^{1}$, Jamaluddin $^{2}$, Gortap Lumbantoruan ${ }^{3}$ \\ 1,2,3 Manajemen Informatika, Universitas Methodist Indonesia \\ 1rimbun.ringo@gmail.com, ${ }^{2}$ jac.satuno@gmail.com, ${ }^{3}$ lumbatoruan.gortap@gmail.com
}

\begin{abstract}
The growth of e-commerce has resulted in massive product information and huge volumes of data. This results in data overload problems. In the case of e-commerce, consumers or users spend a lot of time choosing the goods they need. The urgent question to be answered at this time is how to provide solutions related to intelligent information restrictions so that the existing information is truly information that is by preferences and needs. This research performs information filtering by applying the singular value decomposition method and the Pearson similarity technique to the book recommendation system. The data used is the Book-Crossing Dataset which is the reference dataset for many research recommendation systems. The resulting recommendations are then compared with ecommerce recommendations such as amazom.com. Based on the results of the study obtained data that the results of the recommendations in this study are very good and accurate.
\end{abstract}

Keywords: Singular Value Decomposition, Teknik Similaritas, Pearson Correlation

\section{PENDAHULUAN}

Data lembaga riset pasar e-marketer, jumlah pengguna internet di Indonesia diproyeksikan mencapai 175 juta orang pada tahun 2019 , atau sekitar $65,3 \%$ dari total penduduk 268 juta jiwa. Data dari Dimensional Research, pertumbuhan e-commerce ritel di Indonesia akan tumbuh 133,5\% menjadi US\$ 16,5 miliar atau sekitar Rp 219 triliun pada 2022 (Mansur et al., 2019). Masalah utama yang diakibatkan oleh pertumbuhan e-commerce adalah terjadinya lonjakan arus informasi yang masif serta volume data yang sangat besar (Al-Ghuribi \& Mohd Noah, 2019) sehingga kita diperhadapkan pada masalah overload data (Nilashi et al., 2016). Kondisi ini meningkatkan kompleksitas pengambilan keputusan, dimana keputusan yang diambil tidak akurat dan tidak efektif (Ocón Palma et al., 2020). Pada kasus e-commerce, konsumen atau pengguna menghabiskan waktu yang tidak sedikit dalam memilih barang kebutuhannya. Pertanyaan yang urgen untuk dijawab saat ini adalah bagaimana memberi solusi terkait pembatasan informasi secara cerdas (intelligent) supaya informasi yang ada benar-benar merupakan informasi yang sesuai dengan preferensi dan kebutuhan. Sistem perekomendasi atau recommender system merupakan solusi populer melakukan filterisasi informasi (Zhu et al., 2017), (Liu et al., 2019). Ada dua kategori sistem rekomendasi, sistem klasik dan multi-kriteria. Sistem klasik seperti content based, collaboratif filtering, knowledge based dan hybrid (Chen et al., 2015) memiliki kelemahan utama yaitu keterbatasan rekomendasi hanya berdasarkan satu kriteria saja atau overall rating. Kelemahan kedua adalah sistem klasik memberi rekomendasi tergantung pada frekuensi interaksi pengguna. Hal ini menjadi buruk untuk produkproduk baru atau cold-start yang belum banyak dilirik (Batmaz et al., 2019). Sistem reokmendasi klasik memiliki keterbatasan dalam hal skalabilitas. Ketika bekerja pada data yang sangat besar seperti data MovieLens dan BookCrossing Dataset (Anwar et al., 2021). Sistem rekomenasi tradisional kurang menunjukkan akurasi yang baik. Salah satu solusi untuk mengatasi skalabilitas tersebut adalah faktorisasi matrik (Yuan et al., 2019). Faktorisasi matrik atau matrix factorization adalah penguraian suatu matriks menjadi beberapa buah matrik yang berukuran lebih kecil. Tujuan faktorisasi ini adalah untuk meningkatkan interpretasi data. Pada penelitian ini, faktorisasi matrik dengan metode Singular Value Decomposition atau yang lebih dikenal sebagai SVD diterapkan pada sistem perekomendasi.

\section{ULASAN LITERATUR}

\subsection{Faktorisasi Matrik}

Proses faktorisasi matrik akan memfaktorkan sebuah matriks menjadi lebih dari satu matriks yang lebih kecil (Wang et al., 2017). Singular Value Decomposition atau yang lebih dikenal sebagai SVD, adalah salah satu teknik dekomposisi berkaitan dengan nilai singular (singular value) suatu matriks. Sebuah matrik $A m \times n$. Sebuah 
matrik $A=U \Sigma V^{T}$ adalah sebuah Singular Value Decomposition untuk A dengan $U$ merupakan matriks orthogonal $m \times m, V$ matriks orthogonal $n \times n$ dan $\Sigma$ matriks diagonal $m \times n$ bernilai riil tak negatif yang disebut nilai-nilai singular. Dengan kata lain $\Sigma=\operatorname{diag}(\sigma 1, \sigma 2, \ldots$ , $\sigma$ ) terurut sehingga $\sigma 1 \geq \sigma 2 \geq \ldots \geq \sigma$ n. Jika $U=\left(u_{1}, u_{2}\right.$, $\left.\ldots, u_{\mathrm{n}}\right)$ dan $V=\left(v_{1}, v_{2}, \ldots, v_{\mathrm{n}}\right)$ maka :

$$
A=\sum_{i=1}^{n} \sigma_{i} u_{i} v_{i}^{T}
$$

Teorema tersebut juga menyatakan bahwa matriks Amxn dapat dinyatakan sebagai dekomposisi matriks yaitu matriks $U, \sum$ dan $V$. Matriks $\sum$ merupakan matriks diagonal dengan elemen diagonalnya berupa nilai-nilai singular matriks $A$, sedangkan matriks $U$ dan $V$ merupakan matriks-matriks yang kolom-kolomnya berupa vektor singular kiri dan vektor singular kanan dari matriks $A$ untuk nilai singular yang bersesuaian.

\subsection{SVD pada sistem rekomendasi}

Penerapan faktorisasi matrik dapat diterapkan pada sistem perekomendasi. Matrik $\mathrm{M}$ atau yang sering dikenal dengan user-item matrix (M) dapat di dekomposisi menjadi tiga buah matrik lain, yaitu matrik User-feature (U), matrik sigma $\left(\sum\right)$, dan matrik item-feature matrix $\left(\mathrm{V}^{\mathrm{T}}\right)($ Falk, 2019)

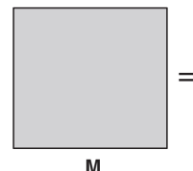

M

U
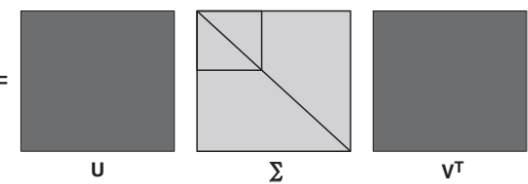

Gambar 1. Faktorisasi Matrik pada Sistem Rekomendasi

\section{METODOLOGI}

\subsection{Alur penelitian}

Alur penelitian ditampilkan pada gambar 1 berikut ini.

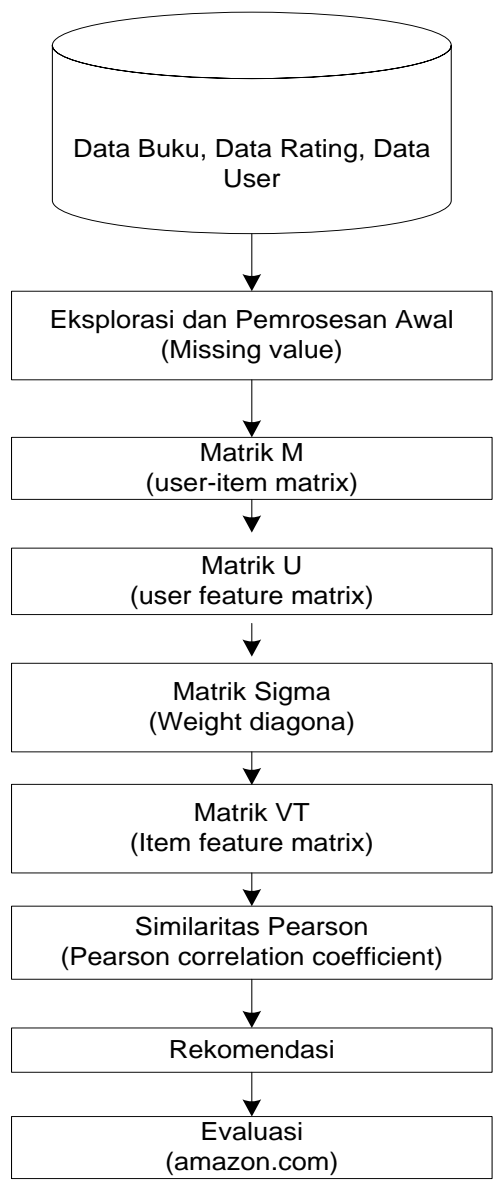

Gambar 1. Alur Penelitian

\subsection{Data}

Data yang digunakan pada penelitian ini adalah BookCrossing Dataset yang bersumber dari http://www2.informatik.uni-freiburg.de/ cziegler/BX/. Terdapat tiga jenis data yang digunakan untuk membangun sistem perekomendasi yaitu buku, data rating, dan data user. Data rating adalah tabel yang berisi userID, ISBN, dan jumah rating buku. Data user berisi userID, lokas, dan usia pembeli. Data buku terdiri ISBN, bookTitle, bookAuthor, yearOfPublication, publisher, imageUrlS, imageUrlM, dan imageUrlL lihat Tabel 1 dan Tabel 2

Tabel 1. Data Rating

\begin{tabular}{|r|r|r|}
\hline userID & ISBN & $\begin{array}{r}\text { Book } \\
\text { wRating }\end{array}$ \\
\hline 276725 & $034545104 X$ & 0 \\
\hline 276726 & 0155061224 & 5 \\
\hline 276727 & 0446520802 & 0 \\
\hline 276729 & $052165615 X$ & 3 \\
\hline 276729 & 0521795028 & 6 \\
\hline
\end{tabular}


Tabel 2. Data User

\begin{tabular}{|r|l|r|}
\hline userID & \multicolumn{1}{|c|}{ Location } & \multicolumn{1}{c|}{ Age } \\
\hline 1 & nyc, new york, usa & nan \\
\hline 2 & stockton, california, usa & 18.000 \\
\hline 3 & moscow, yukon territory, russia & nan \\
\hline 4 & porto, v.n.gaia, portugal & 17.000 \\
\hline 5 & farnborough, hants, united kingdom & nan \\
\hline
\end{tabular}

\section{HASIL DAN PEMBAHASAN}

\subsection{Pemrosesan awal}

Pemrosesa awal bertujun untuk mempersiapkan dataset su paya dapat diproses dengan mudah serta membuang infor masi yang tidak dibutuhkan. Untuk mendapatkan data yan $\mathrm{g}$ representatif, maka perlu dilakukan penggabungan tabel rating dan dan tabel user dengan userID sebagai field kun ci. Sebahagian hasil penggabungan ditampilkan pada Tab el 3 berikut.

Tabel 3. Penggabungan tabel rating dan user

\begin{tabular}{|r|r|c|r|}
\hline userID & ISBN & $\begin{array}{r}\text { Book } \\
\text { Rating }\end{array}$ & bookTitle \\
\hline 276725 & $034545104 \mathrm{X}$ & 0 & Flesh Tones: A Novel \\
\hline 2313 & $034545104 \mathrm{X}$ & 5 & Flesh Tones: A Novel \\
\hline 6543 & $034545104 \mathrm{X}$ & 0 & Flesh Tones: A Novel \\
\hline 8680 & $034545104 \mathrm{X}$ & 5 & Flesh Tones: A Novel \\
\hline 10314 & $034545104 \mathrm{X}$ & 9 & Flesh Tones: A Novel \\
\hline
\end{tabular}

Selanjutnya dilakukan filter data buku yang mengandung missing value serta pengelompokan berdasarkan judul bu ku. Pada tabel 4, user " 2313 " memberi rating " 5 " pada bu ku "034545104X". Total rating buku "Flesh Tones: A No vel" adalah sebesar 60 seperti pada tabel 4 .

Tabel 4. Penggabungan Tabel Rating dan User

\begin{tabular}{|r|c|c|r|c|}
\hline userID & ISBN & $\begin{array}{c}\text { Book } \\
\text { Rating }\end{array}$ & bookTitle & $\begin{array}{r}\text { Total } \\
\text { Rating } \\
\text { Count }\end{array}$ \\
\hline 276725 & $034545104 \mathrm{X}$ & 0 & $\begin{array}{r}\text { Flesh Tones: } \\
\text { A Novel }\end{array}$ & 60 \\
\hline 2313 & $034545104 \mathrm{X}$ & 5 & $\begin{array}{r}\text { Flesh Tones: } \\
\text { A Novel }\end{array}$ & 60 \\
\hline 6543 & $034545104 \mathrm{X}$ & 0 & $\begin{array}{r}\text { Flesh Tones: } \\
\text { A Novel }\end{array}$ & 60 \\
\hline 8680 & $034545104 \mathrm{X}$ & 5 & $\begin{array}{r}\text { Flesh Tones: } \\
\text { A Novel }\end{array}$ & 60 \\
\hline 10314 & $034545104 \mathrm{X}$ & 9 & $\begin{array}{r}\text { Flesh Tones: } \\
\text { A Novel }\end{array}$ & 60 \\
\hline
\end{tabular}

\subsection{Single Value Decomposition (SVD)}

Langkah 1. Setting paremeter.

Parameter SVD yang dibutuhkan adalah jumlah komponen $(k)$. Penentuan jumlah komponen berpengaruh terhadap nilai variance yang dihasilkan. Pada gambar 2 ditampilkan grafik plot antara jumlah komponen dengan nilai variance. Dengan Untuk $k=12$, masih diperoleh nilai variance yang kecil sebesar 0.0587

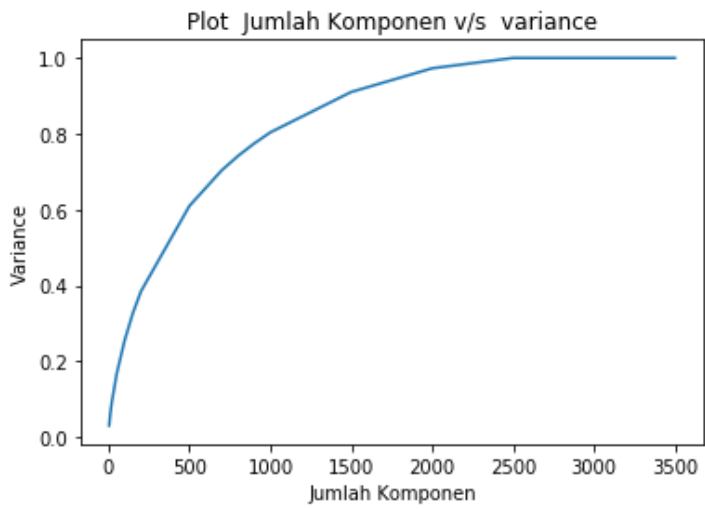

Gambar 1. Plot Jumlah Komponen vs Variance

Langkah 2. Pembentukan matrik utility (M)

Matriks utility disebut juga matriks user-item, yaitu matri $\mathrm{k}$ dua dimensi dengan vipot baris userID dan kolom adal ah bookTitle. Tabel berisi nilai rating setiap item buku. M atrik ini memiliki dimensi $(40017,2442)$. Pada matrik in i, setiap nilai yang kosong atau missing value diganti den gan null

\section{Langkah 3. Matriks singular values}

Untuk jumlah komponen $=12$, matrik singular values merupakan matriks dengan dimensi (kolom, baris $)=(1$, 12) seperti pada Tabel $5 .$.

Tabel 5. Matrik Singular Values

\begin{tabular}{|r|c|}
\hline Index & Singular values \\
\hline 0 & 329.194 \\
\hline 1 & 224.117 \\
\hline 2 & 210.927 \\
\hline 3 & 191.241 \\
\hline 4 & 188.546 \\
\hline 5 & 178.070 \\
\hline 6 & 167.620 \\
\hline 7 & 162.655 \\
\hline 8 & 160.522 \\
\hline 9 & 156.632 \\
\hline 10 & 152.577 \\
\hline 11 & 147.536 \\
\hline
\end{tabular}

\section{Langkah 3. Pembentukan Matrik $U$}

Matrik $U$ atau dikenal dengan User-feature matrix $(U)$ adalah hasil faktorisasi matrik $M$ dengan jumlah baris 2441 dan fitur adalah 12 seperti pada Tabel 6 . 
Tabel 6. Tabel User-feature matrix $(U)$

\begin{tabular}{|c|c|c|c|c|c|c|c|c|c|c|c|c|}
\hline & $\mathbf{0}$ & $\mathbf{1}$ & $\mathbf{2}$ & $\mathbf{3}$ & $\mathbf{4}$ & $\mathbf{5}$ & $\mathbf{6}$ & $\mathbf{7}$ & $\mathbf{8}$ & \multicolumn{1}{c|}{$\mathbf{9}$} & $\mathbf{1 0}$ & $\mathbf{1 1}$ \\
\hline $\mathbf{0}$ & 0.004 & 0.003 & 0.000 & 0.002 & -0.001 & 0.002 & 0.004 & 0.002 & -0.007 & -0.004 & -0.006 & -0.003 \\
\hline $\mathbf{1}$ & 0.010 & 0.000 & -0.016 & 0.015 & -0.021 & 0.006 & -0.036 & -0.008 & -0.010 & -0.013 & -0.014 & -0.004 \\
\hline $\mathbf{2}$ & 0.043 & 0.004 & 0.006 & -0.051 & 0.057 & -0.008 & -0.013 & -0.040 & -0.014 & -0.059 & 0.013 & -0.005 \\
\hline $\mathbf{3}$ & 0.068 & -0.037 & -0.058 & -0.004 & -0.057 & 0.008 & 0.115 & 0.051 & -0.026 & -0.013 & -0.058 & -0.025 \\
\hline $\mathbf{4}$ & 0.013 & 0.004 & -0.009 & -0.000 & 0.008 & -0.004 & -0.025 & -0.022 & 0.005 & -0.023 & 0.005 & -0.000 \\
\hline $\mathbf{5}$ & 0.008 & -0.004 & -0.007 & 0.014 & -0.014 & 0.008 & -0.013 & 0.011 & -0.021 & 0.000 & -0.019 & -0.011 \\
\hline $\mathbf{6}$ & 0.006 & 0.008 & -0.008 & -0.004 & 0.016 & 0.002 & 0.001 & -0.000 & 0.003 & -0.000 & -0.003 & 0.000 \\
\hline $\mathbf{\ldots}$ & $\mathbf{\ldots}$ & $\ldots$ & $\ldots$ & $\ldots$ & $\ldots$ & $\ldots$ & $\ldots$ & $\ldots$ & $\ldots$ & $\ldots$ & $\ldots$ & $\ldots$ \\
\hline $\mathbf{2 4 4 1}$ & 0.005 & 0.001 & 0.004 & -0.006 & 0.002 & 0.008 & -0.004 & -0.001 & -0.004 & -0.008 & -0.004 & -0.005 \\
\hline
\end{tabular}

Langah 4. Pembentukan matrik sigma $\left(\sum\right)$

Matrik sigma adalah matrik diagonal dimana nilai diagonal berisi angka-angka tak negatif sebagaimana ditampilkan pada Tabel 7

Tabel 7. Matrik sigma

\begin{tabular}{|c|c|c|c|c|c|c|c|c|c|c|c|c|}
\hline & 0 & 1 & 2 & 3 & 4 & 5 & 6 & 7 & 8 & 9 & 10 & 11 \\
\hline 0 & 329.194 & 0.000 & 0.000 & 0.000 & 0.000 & 0.000 & 0.000 & 0.000 & 0.000 & 0.000 & 0.000 & 0.000 \\
\hline 1 & 0.000 & 224.117 & 0.000 & 0.000 & 0.000 & 0.000 & 0.000 & 0.000 & 0.000 & 0.000 & 0.000 & 0.000 \\
\hline 2 & 0.000 & 0.000 & 210.927 & 0.000 & 0.000 & 0.000 & 0.000 & 0.000 & 0.000 & 0.000 & 0.000 & 0.000 \\
\hline 3 & 0.000 & 0.000 & 0.000 & 191.241 & 0.000 & 0.000 & 0.000 & 0.000 & 0.000 & 0.000 & 0.000 & 0.000 \\
\hline 4 & 0.000 & 0.000 & 0.000 & 0.000 & 188.546 & 0.000 & 0.000 & 0.000 & 0.000 & 0.000 & 0.000 & 0.000 \\
\hline 5 & 0.000 & 0.000 & 0.000 & 0.000 & 0.000 & 178.070 & 0.000 & 0.000 & 0.000 & 0.000 & 0.000 & 0.000 \\
\hline 6 & 0.000 & 0.000 & 0.000 & 0.000 & 0.000 & 0.000 & 167.620 & 0.000 & 0.000 & 0.000 & 0.000 & 0.000 \\
\hline 7 & 0.000 & 0.000 & 0.000 & 0.000 & 0.000 & 0.000 & 0.000 & 162.655 & 0.000 & 0.000 & 0.000 & 0.000 \\
\hline 8 & 0.000 & 0.000 & 0.000 & 0.000 & 0.000 & 0.000 & 0.000 & 0.000 & 160.522 & 0.000 & 0.000 & 0.000 \\
\hline 9 & 0.000 & 0.000 & 0.000 & 0.000 & 0.000 & 0.000 & 0.000 & 0.000 & 0.000 & 156.632 & 0.000 & 0.000 \\
\hline 10 & 0.000 & 0.000 & 0.000 & 0.000 & 0.000 & 0.000 & 0.000 & 0.000 & 0.000 & 0.000 & 152.577 & 0.000 \\
\hline 11 & 0.000 & 0.000 & 0.000 & 0.000 & 0.000 & 0.000 & 0.000 & 0.000 & 0.000 & 0.000 & 0.000 & $\mathbf{1 4 7 . 5 3 6}$ \\
\hline
\end{tabular}

Langah 4. Pembentukan matrik $V^{T}$
Matrik $\mathrm{V}^{\mathrm{T}}$ adalah item-feature matrix dengan jumlah baris $k=12$ dan fitur item sebesar 40017 .

Tabel 8. Matrik $\mathrm{V}^{\mathrm{T}}$

\begin{tabular}{|c|c|c|c|r|r|r|r|r|r|r|r|r|}
\hline & \multicolumn{1}{|c}{} & $\mathbf{1}$ & $\mathbf{2}$ & $\mathbf{3}$ & $\mathbf{4}$ & $\mathbf{5}$ & $\mathbf{6}$ & $\mathbf{7}$ & $\mathbf{8}$ & $\mathbf{9}$ & $\mathbf{\ldots}$ & $\mathbf{4 0 0 1 6}$ \\
\hline $\mathbf{0}$ & 0.000 & 0.000 & -0.000 & 0.001 & 0.000 & 0.000 & 0.004 & 0.001 & 0.001 & 0.000 & $\ldots$ & 0.001 \\
\hline $\mathbf{1}$ & 0.000 & -0.000 & -0.000 & -0.000 & 0.000 & 0.000 & -0.001 & -0.000 & -0.000 & -0.000 & $\ldots$ & -0.001 \\
\hline $\mathbf{2}$ & -0.000 & 0.000 & 0.000 & -0.001 & -0.000 & -0.000 & 0.003 & 0.001 & -0.002 & -0.001 & $\ldots$ & -0.001 \\
\hline $\mathbf{3}$ & -0.000 & -0.001 & -0.000 & 0.000 & 0.000 & 0.000 & -0.006 & -0.001 & -0.000 & -0.000 & $\ldots$ & 0.000 \\
\hline $\mathbf{4}$ & -0.000 & 0.000 & 0.000 & 0.001 & -0.000 & 0.000 & 0.002 & -0.000 & 0.001 & 0.001 & $\ldots$ & -0.001 \\
\hline $\mathbf{5}$ & 0.000 & -0.000 & 0.000 & 0.001 & -0.000 & -0.000 & -0.000 & -0.001 & 0.000 & 0.000 & $\ldots$ & -0.000 \\
\hline $\mathbf{6}$ & -0.000 & -0.000 & 0.000 & 0.002 & 0.000 & -0.000 & -0.006 & 0.001 & 0.001 & -0.001 & $\ldots$ & 0.002 \\
\hline $\mathbf{7}$ & 0.000 & -0.000 & -0.000 & -0.001 & 0.000 & 0.000 & -0.004 & -0.001 & 0.001 & 0.001 & $\ldots$ & -0.000 \\
\hline $\mathbf{8}$ & -0.000 & 0.000 & 0.000 & 0.001 & -0.000 & 0.000 & 0.002 & -0.000 & 0.000 & -0.000 & $\ldots$ & -0.000 \\
\hline $\mathbf{9}$ & 0.000 & -0.000 & 0.000 & -0.001 & 0.000 & -0.000 & -0.012 & -0.001 & 0.002 & 0.003 & $\ldots$ & 0.000 \\
\hline $\mathbf{1 0}$ & -0.000 & 0.000 & 0.000 & -0.001 & 0.000 & -0.000 & 0.010 & -0.000 & 0.002 & 0.001 & $\ldots$ & -0.001 \\
\hline $\mathbf{1 1}$ & -0.000 & -0.000 & -0.000 & -0.000 & 0.000 & 0.000 & 0.003 & -0.001 & 0.000 & -0.000 & $\ldots$ & -0.001 \\
\hline
\end{tabular}

\section{Langkah 5. Pengukuran similaritas}

Hasil matrik akhir adalah matrik similaritas antar itemitem buku. Similaritas ditentukan berdasarkan Pearson's
$R$ correlation coefficient. Pada tabel 9 ditampilkan smililaritas antar item-item, dimana nilai similariats antar item yang sama adalah bernilai " 1 " 
Tabel 9 Simililaritas Antar Item

\begin{tabular}{|c|c|c|c|c|c|c|c|c|c|c|c|c|c|}
\hline & $\mathbf{0}$ & $\mathbf{1}$ & $\mathbf{2}$ & $\mathbf{3}$ & $\mathbf{4}$ & $\mathbf{5}$ & $\mathbf{6}$ & $\mathbf{7}$ & $\mathbf{8}$ & $\mathbf{9}$ & $\mathbf{1 0}$ & $\boldsymbol{\cdots}$ & $\mathbf{2 4 4 1}$ \\
\hline $\mathbf{0}$ & $\mathbf{1 . 0 0 0}$ & 0.328 & 0.287 & 0.643 & 0.101 & 0.653 & 0.263 & 0.790 & 0.719 & 0.672 & 0.594 & $\ldots$ & 0.549 \\
\hline $\mathbf{1}$ & 0.328 & $\mathbf{1 . 0 0 0}$ & 0.035 & 0.181 & 0.564 & 0.744 & 0.099 & 0.219 & 0.425 & 0.630 & 0.103 & $\ldots$ & 0.275 \\
\hline $\mathbf{2}$ & 0.287 & 0.035 & $\mathbf{1 . 0 0 0}$ & 0.116 & 0.723 & -0.140 & 0.655 & 0.446 & -0.004 & -0.116 & 0.825 & $\ldots$ & 0.692 \\
\hline $\mathbf{3}$ & 0.643 & 0.181 & 0.116 & $\mathbf{1 . 0 0 0}$ & -0.067 & 0.498 & 0.160 & 0.811 & 0.887 & 0.619 & 0.195 & $\ldots$ & 0.191 \\
\hline $\mathbf{4}$ & 0.101 & 0.564 & 0.723 & -0.067 & $\mathbf{1 . 0 0 0}$ & 0.060 & 0.560 & 0.229 & -0.042 & -0.048 & 0.528 & $\ldots$ & 0.451 \\
\hline $\mathbf{5}$ & 0.653 & 0.744 & -0.140 & 0.498 & 0.060 & $\mathbf{1 . 0 0 0}$ & -0.040 & 0.386 & 0.758 & 0.955 & 0.087 & $\ldots$ & 0.284 \\
\hline $\mathbf{6}$ & 0.263 & 0.099 & 0.655 & 0.160 & 0.560 & -0.040 & $\mathbf{1 . 0 0 0}$ & 0.423 & 0.207 & 0.022 & 0.348 & $\ldots$ & 0.351 \\
\hline $\mathbf{7}$ & 0.790 & 0.219 & 0.446 & 0.811 & 0.229 & 0.386 & 0.423 & $\mathbf{1 . 0 0 0}$ & 0.730 & 0.491 & 0.548 & $\ldots$ & 0.565 \\
\hline $\mathbf{8}$ & 0.719 & 0.425 & -0.004 & 0.887 & -0.042 & 0.758 & 0.207 & 0.730 & $\mathbf{1 . 0 0 0}$ & 0.843 & 0.116 & $\ldots$ & 0.213 \\
\hline $\mathbf{9}$ & 0.672 & 0.630 & -0.116 & 0.619 & -0.048 & 0.955 & 0.022 & 0.491 & 0.843 & $\mathbf{1 . 0 0 0}$ & 0.050 & $\ldots$ & 0.316 \\
\hline $\mathbf{1 0}$ & 0.142 & 0.114 & 0.446 & 0.338 & 0.256 & 0.171 & -0.096 & 0.220 & 0.232 & 0.131 & 0.543 & $\ldots$ & 0.417 \\
\hline $\mathbf{\ldots}$ & $\ldots$ & $\ldots$ & $\ldots$ & $\ldots$ & $\ldots$ & $\ldots$ & $\ldots$ & $\ldots$ & $\ldots$ & $\ldots$ & $\ldots$ & $\ldots$ & $\ldots$ \\
\hline $\mathbf{2 4 4 1}$ & 0.549 & 0.275 & 0.692 & 0.191 & 0.451 & 0.284 & 0.351 & 0.565 & 0.213 & 0.316 & 0.822 & $\mathbf{\ldots}$ & $\mathbf{1 . 0 0 0}$ \\
\hline
\end{tabular}

\section{Langkah 6. Penentuan rekomendasi}

Berdasarkan matrik similaritas diatas, maka rekomendasi untuk buku dengan judul "The Green Mile: Coffey's Hands (Green Mile Series)" dengan batas korelasi (corr
<1.0) \&\& (corr>0.9) ditampilkan pada daftar berikut. Judul buku yang ditebalkan adalah buku dengan judul yang tepat dan sangat sesuai dengan judul "The Green Mile: Coffey's Hands (Green Mile Series)".

Tabel 10. Hasil Rekomendasi Buku

\begin{tabular}{|l|l|}
\hline No & \multicolumn{1}{|c|}{ Judul } \\
\hline 1 & Needful Things \\
\hline 2 & The Bachman Books: Rage, the Long Walk, Roadwork, the Running Man \\
\hline 3 & The Green Mile: Coffey on the Mile (Green Mile Series), \\
\hline 4 & The Green Mile: Night Journey (Green Mile Series), \\
\hline 5 & The Green Mile: The Bad Death of Eduard Delacroix (Green Mile Series), \\
\hline 6 & The Green Mile: The Mouse on the Mile (Green Mile Series), \\
\hline 7 & The Shining, \\
\hline 8 & The Two Dead Girls (Green Mile Series)] \\
\hline
\end{tabular}

Hasil rekomendasi pada tabel di atas dapat dibadingkan dengan sistem rekomendasi yang diperoleh pada situs ecommerce amazon.com. Dengan memasukkan kata kunci pencarian buku "The Green Mile: Coffey's Hands (Green Mile Series) " maka hasil yang diperoleh sangat mirip atau akurat seperti pada gambar 3 berikut.

amazon $\odot$ Deliver to $\quad$ Books * The Green Mile: Coffey's Hands (Green Mile Series)

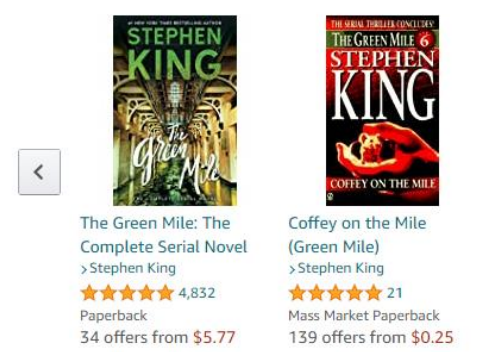

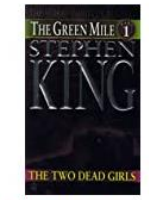

The Two Dead Girls (Green Mile Series, Part 1)

1)

>Stephen King

43

Mass Market Paperback
157 offers from $\$ 0.99$

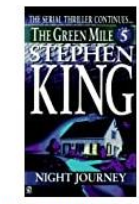

The Night Journey (The Green Mile, Part 5) Stephen King Mañ 10 143 offers from $\$ 0.25$

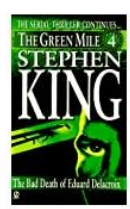

Green Mile book 4: The Bad Death of Eduard Delacroix: The Green Delacroix: The Green Mile, Part 4 $>$ Stephen King

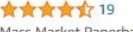
143 offers from $\$ 0.25$

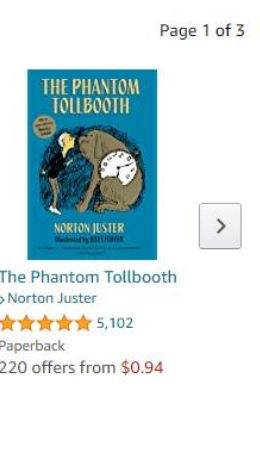

Gambar 3. Hasil rekomendasi pada amazon.com 


\section{KESIMPULAN}

Sistem perekomendasi dengan metode singular value decomposition atau SVD dapat mengatasi masalah sparse matrix yang sering menjadi kendala pada Sistem perekomendasi konvesional. Penelitian ini menerapkan Sistem perekomendasi dengan SVD dan teknik similaritas Pearson. Hasil penelitian menunjukkan bahwa penerapan teknik Pearson pada SVD dapat memberikan hasil rekomendasi yang baik. Hasil penelitian ini masih perlu diperbaiki dengan memperluas penerapan pada dataset yang lain supaya hasil yang diperoleh lebih teruji.

\section{DAFTAR PUSTAKA}

[1]. Al-Ghuribi, S. M., \& Mohd Noah, S. A. (2019). MultiCriteria Review-Based Recommender System-The State of the Art. IEEE Access, 7, 169446-169468. https://doi.org/10.1109/ACCESS.2019.2954861

[2]. Anwar, T., Uma, V., \& Srivastava, G. (2021). RecCFSVD++: Implementing Recommendation System Using Collaborative Filtering and Singular Value Decomposition (SVD)++. International Journal of Information Technology \& Decision Making, 1-19. https://doi.org/10.1142/S0219622021500310

[3]. Batmaz, Z., Yurekli, A., Bilge, A., \& Kaleli, C. (2019). A Review on Deep Learning for Recommender Systems: Challenges and Remedies. Artif. Intell. Rev., 52(1), 1-37. https://doi.org/10.1007/s10462-018-9654-y

[4]. Chen, L., Chen, G., \& Wang, F. (2015). Recommender Systems Based on User Reviews: The State of the Art. User Modeling and User-Adapted Interaction, 25(2), 99-154. https://doi.org/10.1007/s11257-015-9155-5

[5]. Falk, K. (2019). Practical Recommender Systems. Simon and Schuster.

[6]. Liu, X., Su, X., Ma, J., Zhu, Y., Zhu, X., \& Tian, H. (2019). Information filtering based on eliminating redundant diffusion and compensating balance. International Journal of Modern Physics B, 33(13), 1950129. https://doi.org/10.1142/S0217979219501297

[7]. Mansur, D., Sule, E., Kartini, D., \& Oesman, Y. M. (2019). Trust and Habit As Key Success on Digital Consuming Behavior in Indonesia Mediated By Behavior Intention. AFEBI Management and Business Review, 3(02), 16. https://doi.org/10.47312/ambr.v3i02.197

[8]. Nilashi, M., Dalvi-esfahani, M., Zamani, M., Ramayah, T., \& Ibrahim, O. (2016). A Multi-Criteria Collaborative Filtering Recommender System Using Clustering and Regression Techniques. Journal of Soft Computing and Decision Support Systems, 3(5), 24-30.

[9]. Ocón Palma, M. del C., Seeger, A.-M., \& Heinzl, A. (2020). Mitigating Information Overload in e-Commerce Interactions with Conversational Agents. In F. D. Davis, R. Riedl, J. vom Brocke, P.-M. Léger, A. Randolph, \& T. Fischer (Eds.), Information Systems and Neuroscience (pp. 221-228). Springer International Publishing.

[10].Wang, X., Zhong, Y., Zhang, L., \& Xu, Y. (2017). Spatial
Group Sparsity Regularized Nonnegative Matrix Factorization for Hyperspectral Unmixing. IEEE Transactions on Geoscience and Remote Sensing, 55(11), 6287-6304. https://doi.org/10.1109/TGRS.2017.2724944

[11].Yuan, X., Han, L., Qian, S., Xu, G., \& Yan, H. (2019). Singular value decomposition based recommendation using imputed data. Knowledge-Based Systems, 163, 485-494. https://doi.org/https://doi.org/10.1016/j.knosys.2018.09.01 1

[12].Zhu, X., Tian, H., Chen, G., \& Cai, S. (2017). Symmetrical and overloaded effect of diffusion in information filtering. Physica A: Statistical Mechanics and Its Applications, 483, 9-15.

https://doi.org/https://doi.org/10.1016/j.physa.2017.04.087 